\title{
To Determine the Effect of Dimpled Poppet Valve on the Flow in Engine Cylinder by Port Flow Simulation
}

\author{
Anirudh Singh ${ }^{1}$, Apoorv Dubey ${ }^{1}$ and Raj Kumar Singh ${ }^{1}$ \\ ${ }^{1}$ Mechanical Engineering Department, Delhi Technological University, Delhi 42, India
}

\begin{abstract}
Intake system is one of the crucial sub-systems in engine, the geometrical configuration of the inlet ports and the valves and their opening schedule creates organized motions in the cylinder, known as swirl (about the cylinder axis) and tumble (orthogonal to the cylinder axis) which help in proper mixing of fuel and air. Surface texturing of intake valve can improve the performance of engine drastically by generating more swirl, turbulent kinetic energy and reducing the coefficient of skin friction in the valve proximity area. Making dimples on intake valve is one of the many ways in which surface texturing can be done and its effectiveness can be easily measured by conducting a steady-state port flow simulation on ANSYS IC fluent solver using standard k-omega model. Port flow analysis was carried on dimpled intake valve at a lift of $5 \mathrm{~mm}$ for 5 dimple ratio ranging from 0.1 to 0.3 in steps of 0.05 . The dimple depth-over diameter ratio is a very crucial parameter in determining the optimum geometry of dimple on which best results are obtained. The results showed that the maximum mass flow rate is obtained at dimple ratio of 0.2 with an increase of $0.005 \%$ over the simple intake valve and a $38.4 \%$ decrease in the area weighted average skin friction coefficient in valve proximity area was seen in case of dimpled valve.
\end{abstract}

\section{Introduction}

The 4 stroke internal combustion engine consists of four cycles namely intake, compression, power stroke and exhaust. Out of these four processes, intake and compression strokes are the most important as these strokes have great effect on determining the pattern of air flow coming inside cylinder during intake stroke and the condition needed for the proper vaporization and mixing of fuel during fuel injection in compression stroke[1]. For maximizing the air passing into the cylinder, intake valve design has to be optimized. Hence optimum design of intake valve is crucial in engine design. Xiaofeng Yang, Zhaohui Chen, and Tang-Wei Kuo described that the development and optimization of intake system is to find the best trade-off between a) minimum flow restriction (discharge coefficient or volumetric efficiency) and b) an optimal in-cylinder charge motion (swirl or tumble ratios) [2]. Chenbo Ma, Jianjun Sun, Yan Wang, Bo Yu , Qiuping Yu and Qiaoan Tu stated surface texturing as a viable technique to significantly enhance the loadcarrying capacity, friction coefficient, and wear resistance of vital components and to maximize the effect of surface texturing, many theoretical and experimental studies have been carried out that concentrate on the geometrical parameters of textures[3]. Etsion I. stated that to fully benefit from surface texturing, a proper optimization of the geometrical parameters, including the dimple depth- over diameter ratio (DOD) and area density, must be performed [4]. Therefore, the determination of the optimum dimple DOD ratio is very important. This concept of surface texturing was used to introduce dimples on the poppet valve and then measuring its effectiveness by conducting the Port flow simulation on ANSYS IC Fluent solver.

\section{Flow in cylinder}

All fluid flow is either laminar or turbulent, whether a flow is laminar or turbulent is usually determined by the Reynolds number. The flow in the cylinder is divided into several distinct phases. Firstly, the geometrical configuration of the intake system and the opening schedule of the inlet valves creates organized motions in the cylinder, known as swirl (about the cylinder axis) and tumble (orthogonal to the cylinder axis) and second, the jet itself is turbulent, and in addition much of the directed (non-turbulent) energy in the jet is converted to turbulence, resulting in a very high turbulence level during the inlet stroke[5]. The flow through the inlet valve forms a hollow conical jet, which is roughly equal to the angle of the valve seat.

An air flow bench is a device used for testing the internal aerodynamic qualities of an engine component and is used primarily for testing the intake and exhaust ports of cylinder heads of internal combustion engines. A 
flow bench consists of an air pump, a metering element, temperature and pressure measuring instruments such as manometers, and various controls. The test piece is connected in series with the pump and measuring element and air is pumped through the whole system. As the volume flow rate through the metering element is known which is equal to the flow through the test piece, the mass flow rate can be calculated using the known pressure and temperature data to calculate air densities, and then multiplied by the volume flow rate. Most flow testing is done between 10 and 28 inches of water pressure ( 2.5 to 7 kilopascals).

Nur Adila Mohamad Shafie et al.[6] showed that the minimum and maximum deviation as small as $1.6 \%$ and $5.1 \%$ respectively were obtained when they compared the results obtained by port flow simulation and those obtained from engine flow bench test(experimental test) which shows that port flow simulation can accurately predict the breathing parameter of engine.

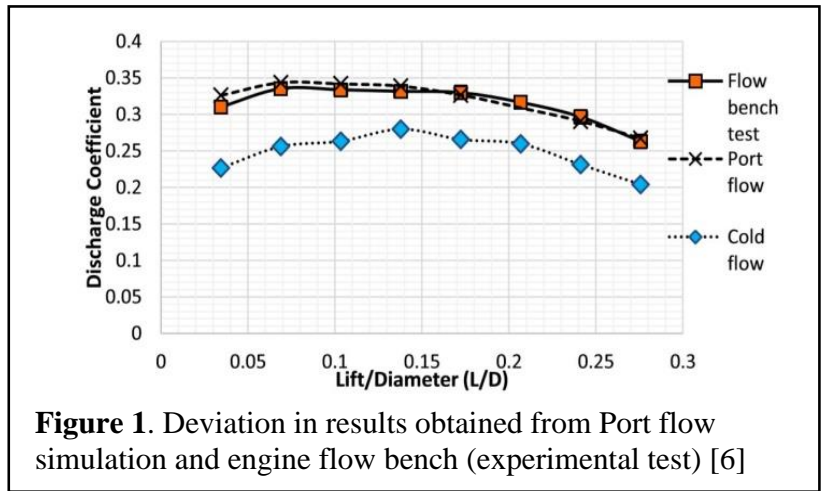

\section{Methodology}

A simplified design of port has been used for conducting this simulation, the design of intake plenum, outplenum, cylinder and port is kept same for all the cases in order to compare the effect of introducing dimples on the poppet valve over the simple valve. In case of the dimpled valves, two sets of 20 equidistant dimples were introduced on the valve. The print diameter of the dimples is kept at a constant of $1.2 \mathrm{~mm}$ and the depth of the dimple is varied, governed by the dimple ratio $h /{ }_{D}=\mathrm{c}$ (here $\mathrm{D}=$ print diameter, $\mathrm{h}=$ depth, $\mathrm{c}=$ constant ranging from 0.1 to 0.3 in steps of 0.05). The port flow analysis in all the cases is carried out at an intake valve lift of $5 \mathrm{~mm}$ and the exhaust port is deactivated by defining the exhaust valve lift to be $0 \mathrm{~mm}[7]$.

The placement of dimples on poppet valve can be seen in fig. 2 for more better understanding of the geometry on which analysis is being carried upon, their configuration as well as their shape have a great effect on various parameters like drag, skin friction coefficient, standton number and reynolds number of the flow[8].

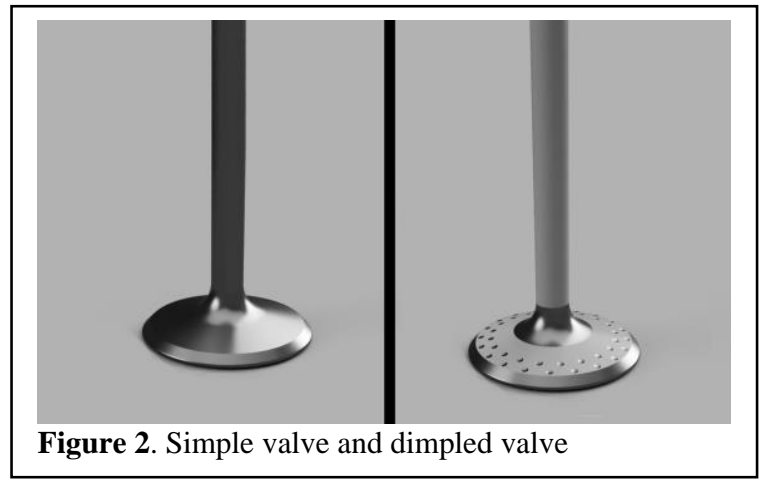

\subsection{Decomposition and meshing}

The assembled model is then defined in the IC Input Manager in the design modeler and decomposed into the intake, exhaust ports and the cylinder. Four post planes (swirl planes) were added at a distance of $15 \mathrm{~mm}, 30 \mathrm{~mm}$, $45 \mathrm{~mm}$ and $60 \mathrm{~mm}$ from the reference point for analyzing the swirl and velocity distribution due to introduction of dimples on poppet valve. Values of various parameters inserted in the input manager are shown in the Fig. 3.

The decomposed geometry is then meshed using a hybrid mesh topology. The maximum mesh size is reduced to $2.5 \mathrm{~mm}$, the number of inflation layers is increased to 12 and the chamber growth rate is reduced to 1.12. The size of the elements in the valve proximity area is kept at $0.2 \mathrm{~mm}$ to capture the properties of flow precisely in that area. The inflation layers are essential for capturing the features of the boundary layers perfectly as prismatic elements provide good alignment with the flow near wall boundaries and thus special emphasis is laid on them. For regions other than the boundary layers, tetrahedral elements are predominant. The values of various mesh parameters are shown in Table 1.

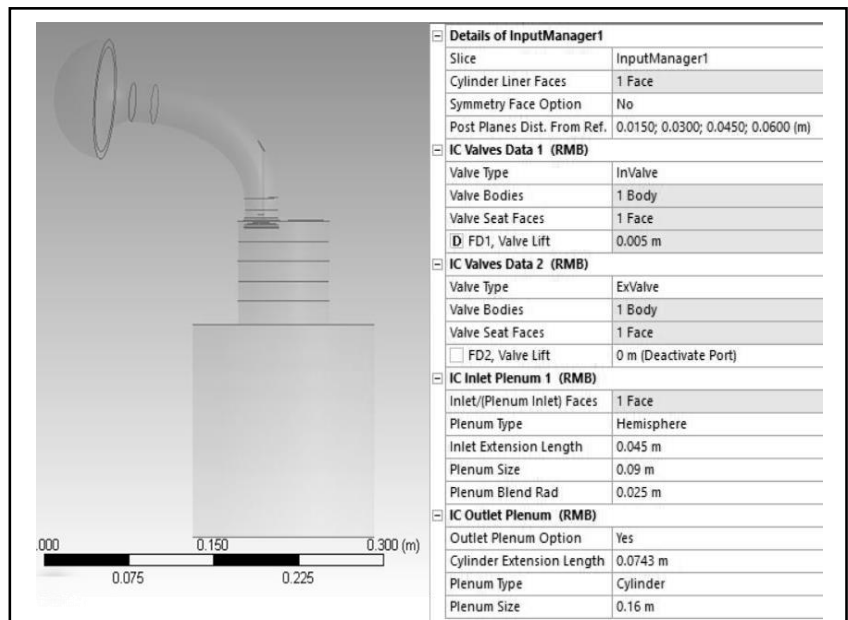

Figure 3. Decomposed geometry and input parameters 
Table 1. IC Port Mesh Parameters

\begin{tabular}{|l|l|l|}
\hline S.no & Mesh Parameters & Input value \\
\hline 1 & Mesh type & Hybrid \\
\hline 2 & Reference size $(\mathrm{mm})$ & 0.993 \\
\hline 3 & Maximum mesh size $(\mathrm{mm})$ & 2.5 \\
\hline 4 & Curvature normal angle(degree) & 18 \\
\hline 5 & Number of cell across gap & 5 \\
\hline 6 & Number of inflation layer & 12 \\
\hline 7 & Chamber size $(\mathrm{mm})$ & 1.2 \\
\hline 8 & Chamber growth rate & 1.12 \\
\hline 9 & Valve proximity face size $(\mathrm{mm})$ & 0.2 \\
\hline
\end{tabular}

\subsection{Solver Setup}

For the purpose of simulation, standard k-omega model is used and the boundary conditions applied on various surfaces is shown in Table 2. An area weighted average surface monitor was set on the ice-int-chamber2outplenum and a convergence monitor was applied on the plane with convergence criteria of $1 * 10^{-5}$ and the numbers of iterations to be ignored was set to 600 . Different zones on which boundary condition is applied can be seen in Fig. 4.

Table 2. Boundary conditions

\begin{tabular}{|c|c|c|c|c|}
\hline S.no & Zones & Type & Temperature & $\begin{array}{c}\text { Gauge } \\
\text { Pressure(Pa) }\end{array}$ \\
\hline 1 & $\begin{array}{c}\text { ice- } \\
\text { slipwall- } \\
\text { outplenum }\end{array}$ & wall & $300 \mathrm{~K}$ & $\mathrm{X}$ \\
\hline 2 & $\begin{array}{c}\text { ice- } \\
\text { slipwall- } \\
\text { inplenum }\end{array}$ & wall & $300 \mathrm{~K}$ & $\mathrm{X}$ \\
\hline 3 & $\begin{array}{c}\text { ice-outlet } \\
\text { pressure } \\
\text { outlet }\end{array}$ & $300 \mathrm{~K}$ & 5000 \\
\hline 4 & $\begin{array}{c}\text { ice-inlet- } \\
\text { inplenum1 }\end{array}$ & $\begin{array}{c}\text { pressure } \\
\text { inlet }\end{array}$ & $300 \mathrm{~K}$ & 0 \\
\hline
\end{tabular}

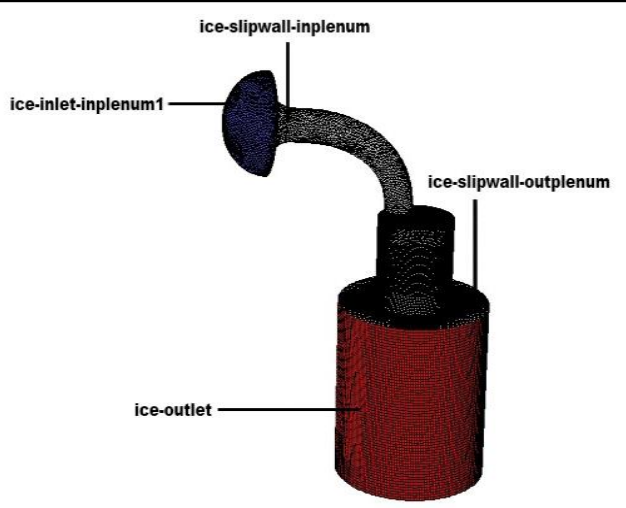

Figure 4. Different Zones on which boundary condition is applied
Once the solution had converged, obtained results were analyzed for all the case.

\section{Result And Discussion}

To compare the results obtained from port flow simulation conducted with simple intake poppet valve to that obtained from dimpled intake poppet valve with various dimple ratios, some key parameters were focused upon. In total four major parameters were studied to determine the effect of introduction of dimples on the incylinder flow. These parameters are as follows:

\subsection{Mass Flow Rate}

Mass flow rate is one of the many parameters that is given major focus upon as it determines the ability of intake port by which the engine can move the charge of air into and out of the cylinder. The results obtained after port flow simulation for dimple ratio from 0.1-0.3 showed that we get maximum mass flow rate of $34.663 \mathrm{~g} / \mathrm{s}$ at the dimple ratio of 0.2 . Fig. 5 shows the variation of mass flow rate $(\mathrm{g} / \mathrm{s})$ to the dimple ratio $(\mathrm{h} / \mathrm{D})$. The curve shows that the mass flow rate increases for dimple ratio from 0.1 to maximum at 0.2 and the suddenly decreases for dimple ratio from 0.2 to 0.3 . Thus it can be concluded that there is an optimum valve of dimple ratio that will increase our mass flow rate for the same port design. The mass flow rate obtained for the simple valve was $34.661 \mathrm{~g} / \mathrm{s}$. Thus there is a small increase in mass flow rate of $0.005 \%$. The value of mass flow rate obtained for other dimple ratios can be seen in Table 3.

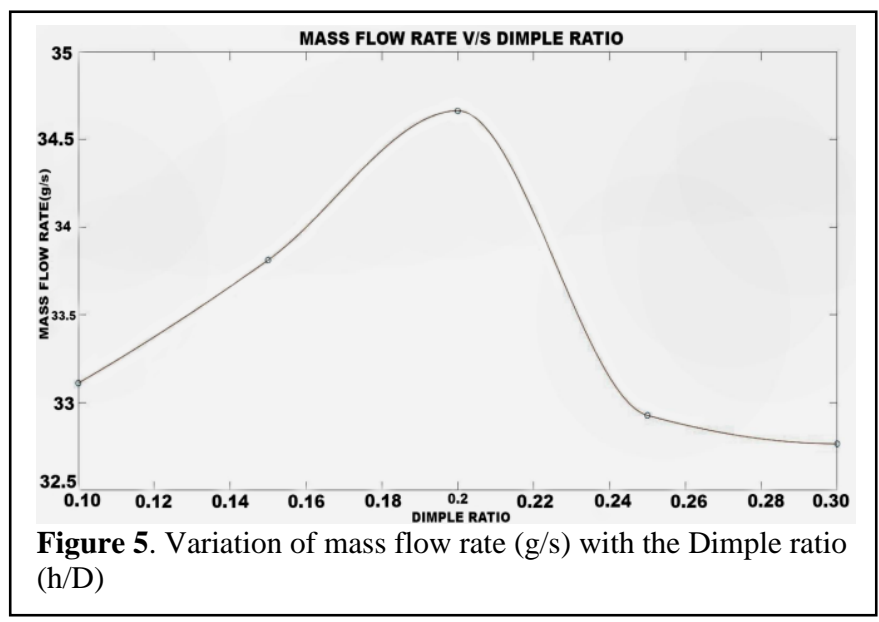

\subsection{Turbulent Kinetic Energy}

Mohd Aizad Sazrul Sabrudin, Mohd Farid Muhamad Said and Zulkarnain Abdul Latiff tried to study the effect of asymmetric intake valve lift configuration towards incylinder air flow behaviour by conducting a steady state port flow simulation and described that Turbulent kinetic energy (TKE) measurement on swirl monitoring planes is one of the methods that can be used to visualize the flow mixture behaviour inside the combustion chamber [9]. 
Instead of focussing on maximum or minimum turbulent kinetic energy $\left(\mathrm{m}^{2} / \mathrm{s}^{2}\right)$ obtained on the swirl plane, focus on the area weighted average turbulent kinetic energy on the first swirl plane (SWIRL PLANE-1) was laid. Table 3 shows the value of area weighted average turbulent kinetic energy obtained on the first swirl plane monitor formed during the geometry decomposition process.

\subsection{Swirl}

There are a number of reasons for inducing swirl. High turbulence levels at ignition produce higher effective flame speeds, and more reliable combustion at very lean ratios, or with exhaust gas recirculation. At normal air/fuel ratios, the higher speed will allow the flame front to reach the end gas before the chemical reaction resulting in auto ignition has time to take place, permitting higher compression ratios without knock, the idea of swirl or tumble is to encapsulate some momentum of the inlet valve jet in the organized motion (swirl or tumble), which is less dissipative than the turbulence. The value of area weighted average swirl obtained on all four swirl planes for all the cases is shown in Table 3.

\subsection{Coefficient of Skin Friction in Valve Proximity Area}

According to Superflow Technologies Flowbench Operators' Manual and study conducted by Abdul Rahim Ismail et al.[10,11], source of flow losses in the port are wall friction, bend at valve guide, contraction at push-rod, expansion behind valve guide, expansion in 25 and 30 degrees, bend at the exit of the valve and expansion exiting valve. These sources of flow losses can be seen in Fig. 6.

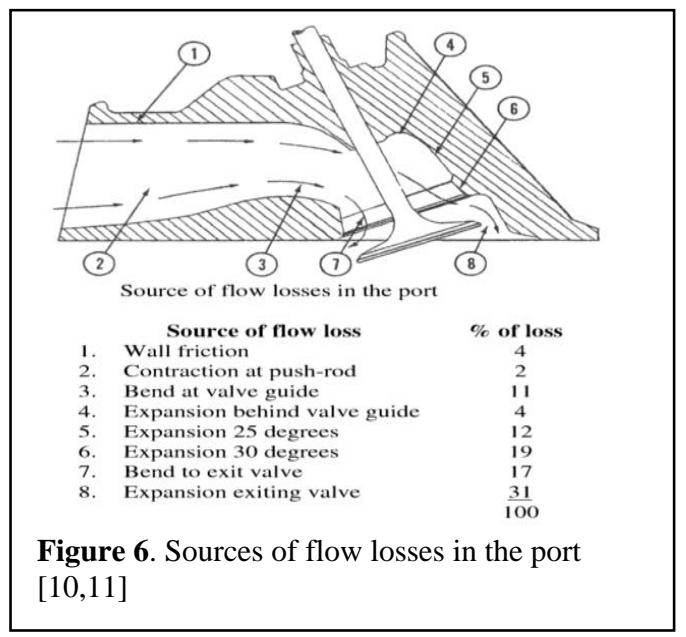

The area weighted average of skin friction coefficient in the valve proximity area was analyzed and it can be seen from Table 3. that for all values of dimple ratio(0.10.3 ), the area weighted average of skin friction coefficient in valve proximity area was less than that in case of simple intake poppet valve. Also, it can be seen from Fig.7 that as the dimple ratio is increased from 0.1 to 0.3 there is an increase in the coefficient of skin friction in the valve proximity area.

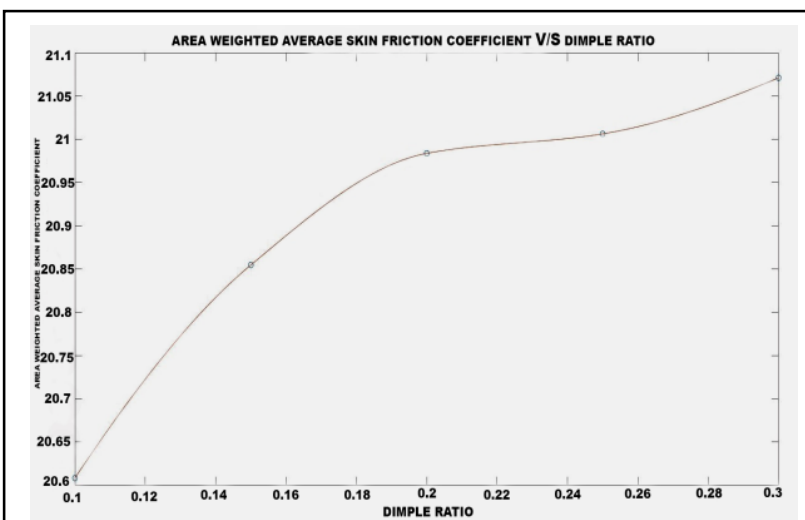

Figure 7. Variation of area-weighted average skin friction coefficient with dimple ratio

The lowest value of area weighted average skin friction coefficient(20.608) is obtained with a dimple ratio of 0.1 , while the value of area weighted average skin friction coefficient obtained in case of simple valve is 33.507.Thus the skin friction coefficient of valve is decreased by $38.4 \%$ due to introduction of dimples.

The velocity distribution on all the swirl planes as well as cutplane for all the cases can be seen in Fig. 8 . Major focus was given upon these four parameters to evaluate the effectiveness of the dimples created on the valve.

Table 3. Values of various parameters obtained for all the cases

\begin{tabular}{|c|c|c|c|c|c|c|}
\hline \multirow{2}{*}{$\begin{array}{l}\text { Paramete } \\
\mathbf{r}\end{array}$} & \multirow{2}{*}{$\begin{array}{l}\text { Simple } \\
\text { Valve }\end{array}$} & \multicolumn{5}{|c|}{ Dimpled Valve } \\
\hline & & 0.1 & 0.15 & 0.2 & 0.25 & 0.3 \\
\hline $\begin{array}{l}\text { Mass flow } \\
\text { rate }(\mathrm{g} / \mathrm{s})\end{array}$ & 34.661 & $\begin{array}{l}33.1 \\
11\end{array}$ & $\begin{array}{l}33.8 \\
12\end{array}$ & $\begin{array}{l}34.6 \\
63\end{array}$ & $\begin{array}{l}32.9 \\
27\end{array}$ & $\begin{array}{l}32.7 \\
65\end{array}$ \\
\hline $\begin{array}{l}\text { Turbulent } \\
\text { kinetic } \\
\text { energy }\left(\mathrm{m}^{2}\right. \\
\left./ \mathrm{s}^{2}\right)\end{array}$ & 48.41 & $\begin{array}{l}53.2 \\
5\end{array}$ & $\begin{array}{l}52.3 \\
3\end{array}$ & $\begin{array}{l}51.5 \\
6\end{array}$ & $\begin{array}{l}58.7 \\
5\end{array}$ & $\begin{array}{l}57.5 \\
7\end{array}$ \\
\hline $\begin{array}{l}\text { Skin } \\
\text { friction } \\
\text { coefficient }\end{array}$ & 33.507 & $\begin{array}{l}20.6 \\
08\end{array}$ & $\begin{array}{l}20.8 \\
54\end{array}$ & $\begin{array}{l}20.9 \\
83\end{array}$ & $\begin{array}{l}21.0 \\
06\end{array}$ & $\begin{array}{l}21.0 \\
71\end{array}$ \\
\hline $\begin{array}{l}\text { Swirl on } \\
\text { Swirl } \\
\text { plane-1 }\end{array}$ & -0.02 & $\begin{array}{l}0.00 \\
7\end{array}$ & $\begin{array}{l}0.02 \\
2\end{array}$ & $\begin{array}{l}0.02 \\
3\end{array}$ & $\begin{array}{l}0.01 \\
5\end{array}$ & $\begin{array}{l}0.03 \\
6\end{array}$ \\
\hline $\begin{array}{l}\text { Swirl on } \\
\text { Swirl } \\
\text { plane-2 }\end{array}$ & -0.05 & $\begin{array}{l}0.01 \\
3\end{array}$ & $\begin{array}{l}0.04 \\
1\end{array}$ & $\begin{array}{l}0.02 \\
9\end{array}$ & $\begin{array}{l}0.04 \\
4\end{array}$ & $\begin{array}{l}0.03 \\
5\end{array}$ \\
\hline $\begin{array}{l}\text { Swirl on } \\
\text { Swirl } \\
\text { plane-3 }\end{array}$ & -0.04 & $\begin{array}{l}0.01 \\
37\end{array}$ & 0.07 & $\begin{array}{l}0.03 \\
6\end{array}$ & $\begin{array}{l}0.01 \\
9\end{array}$ & $\begin{array}{l}0.07 \\
8\end{array}$ \\
\hline $\begin{array}{l}\text { Swirl on } \\
\text { Swirl } \\
\text { plane-4 }\end{array}$ & -0.01 & $\begin{array}{l}0.04 \\
6\end{array}$ & $\begin{array}{l}0.01 \\
8\end{array}$ & $\begin{array}{l}0.05 \\
5\end{array}$ & $\begin{array}{l}0.01 \\
1\end{array}$ & 0.12 \\
\hline
\end{tabular}




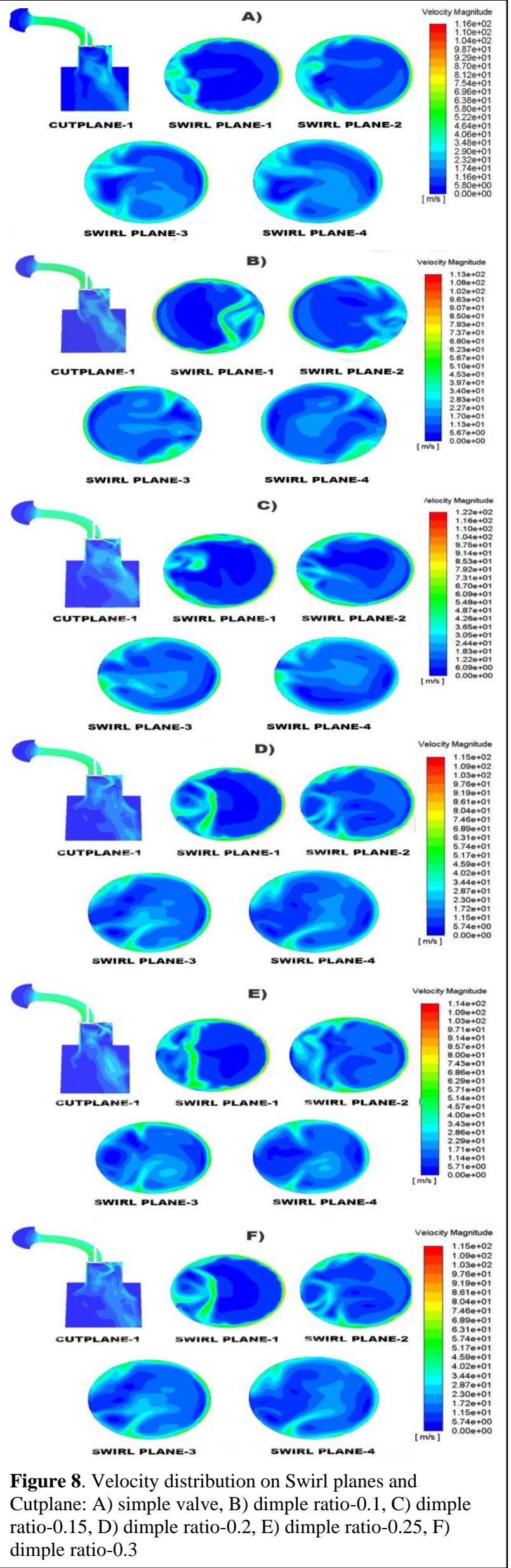

\section{Conclusion}

In this work, the effect of introduction of dimples on the intake valve on the various performance characteristics of the engine was studied. The port flow simulation was carried with gauge outlet pressure of $5000 \mathrm{~Pa}$ and the intake valve was given a lift of $5 \mathrm{~mm}$. Port flow analysis was carried on dimpled intake valve at a lift of $5 \mathrm{~mm}$ for 5 dimple ratio ranging from 0.1 to 0.3 in steps of 0.05 . The main conclusions are as follows:

1. The results obtained after port flow simulation for dimple ratio from 0.1-0.3 showed that we get maximum mass flow rate of $34.663 \mathrm{~g} / \mathrm{s}$ at the dimple ratio of 0.2 . The mass flow rate increases for dimple ratio from 0.1 to maximum at 0.2 and the suddenly decreases for dimple ratio from 0.2 to 0.3 .

2. The lowest value of area weighted average skin friction coefficient(20.608) is obtained with a dimple ratio of 0.1 , while the value of area weighted average skin friction coefficient obtained in case of simple valve is 33.507.Thus the skin friction coefficient of valve is decreased by $38.4 \%$ due to introduction of dimples.

3. The value of area weighted Turbulent Kinetic energy $\left(\mathrm{m}^{2} / \mathrm{s}^{2}\right)$ on SWIRL PLANE-1 was found to be greater in case of dimpled valve for every dimple ratio over the normal valve.

4. Higher value of swirl obtained on each swirl plane in case of dimpled valve shows the ability of the engine to mix air and fuel properly and effectively, that will enable a controlled as well as high speed flame front which will produce more power for the same quantity of the provided fuel.

\section{References}

[1] Heywood JB Internal Combustion Engine Fundamentals. Mcgraw-Hill; 1989

[2] Yang X, Chen Z, Kuo T Pitfalls for accurate steadystate port flow simulations. Journal of Engineering for Gas Turbines and Power 2013;135(6):061601061601

[3] Ma C, Sun J, Wang Y, et al. On the optimum dimple depth-over-diameter ratio for textured surfaces. Adv. Mech Eng 2017; 9: 1-8.

[4] Etsion I, Kligerman Y and Halperin G. Analytical and experimental investigation of laser-textured mechanical seal faces. Tribol T 1999; 42: 511-516.

[5] FLOW IN THE CYLINDER by John L. Lumley, Cornell University (excerpt from his book: Engines an introduction. Cambridge University Press, 1999)

[6] Nur Adila Mohamad Shafie, Mohd Farid Muhamad Said, Azhar Abdul Aziz, Zulkarnain Abdul Latiff, Ahmad Kamal Mat Yamin and Noreffendy Tamaldin MATEC Web Conf., 90 (2017) 01067, DOI: https://doi.org/10.1051/matecconf/20179001067 
[7] Winroth, P.M., Ford, C.L. \& Alfredsson, P.H. Exp Fluids (2018) 59: $24 . \quad$ DOI: https://doi.org/10.1007/s00348-017-2478-8

[8] Leontiev A I, Kiselev N A, Vinogradov Y A, Strongin M M, Zditovets A G and Burtsev S A 2017 Experimental investigation of heat transfer and drag on surfaces coated with dimples of different shape Int. J. Therm. Sci.118152-67

[9] Mohd Aizad Sazrul Sabrudin, Mohd Farid Muhamad Said and Zulkarnain Abdul Latiff. Effects of Asymmetric Intake Valve Lift Configuration Towards In-Cylinder Air Flow Behaviour. ARPN
Journal of Engineering and Applied Sciences; VOL. 12, NO. 7, APRIL 2017

[10] SuperFlow Technologies Group, 2004. SF-1020 Flowbench Operators' Manual, SuperFlow Corporation, Colorado Springs, USA.

[11] Abdul Rahim Ismail, Rosli Abu Bakar and Semin, An Investigation of Valve Lift Effect on Air Flow and Coefficient of Discharge of Four Stroke Engines Based on Experiment,American Journal of Applied Sciences 5 (8): 963-971, 2008, ISSN 1546-9239. 